\title{
Pengaruh Word Of Mouth (WOM) Dan Brand Image Terhadap Keputusan Penggunaan Jasa Foto Pada Studio Foto 4 Warna Photography Kota Kediri
}

\author{
Yeziga Enggar; Gandung Satriyono; Nursamsu \\ Fakultas Ekonomi - Universitas Kadiri \\ E-mail : gandungsatriyono@ unik-kediri.ac.id
}

\begin{abstract}
The research aims to analyze and determine the effect of Word of Mouth and Brand Image on the decision to use photo services on 4 colors of Kediri City Photography. This research uses quantitative methods. The type of research used is the correlation with sampling techniques. The research sample was 60 respondents in number. The multiple linear regression analysis technique is tested for validity and reliability first. The conclusion of this study is (1) Word of Mouth has a significant effect on the decision to use photo services on 4 colors of photography. (2) Brand image has a significant effect on the Decision of Using Photo Services on 4 Colors of Photography. (3) Simultaneously or together two independent variables consisting of word of mouth, brand image has a significant effect on service use decisions.
\end{abstract}

Keywords: Word Of Mouth (WOM), Brand Image, Purchasing Decision, Photography

\section{ABSTRAK}

Penelitian bertujuan menganalisis dan mengetahui pengaruh Word Of Mouth dan Brand Image terhadap Keputusan Penggunaan Jasa foto pada 4 Warna Photography Kota Kediri. Penelitian ini menggunakan metode kuantitatif. Jenis penelitian yang digunakan penelitian adalah korelasi dengan teknik pengambilan sampel. Sampel penelitian 60 responden jumlahnya. Teknik analisis regresi linier berganda dengan terlebih dahulu di uji validitas dan reliabilitas. Kesimpulan penelitian ini adalah (1) Word Of Mouth berpengaruh signifikan terhadap Keputusan Penggunaan Jasa Foto pada 4 Warna Photography. (2) Brand image berpengaruh signifikan terhadap Keputusan Penggunaan Jasa Foto pada 4 Warna Photography. (3) Secara simultan atau bersama - sama dua variabel bebas yang terdiri dari word of mouth, brand image berpengaruh signifikan terhadap keputusan penggunaan jasa.

Kata Kunci : Word Of Mouth (WOM), Brand Image, Keputusan Pembelian, Photography

\section{PENDAHULUAN}

Menawarkan sebuah aktivitas atau kegiatan yang dilakukan oleh pihak penyedia kepada konsumen yang bersifat tak berwujud serta tidak adanya pindah tangan kepemilikan apapun dalam proses tawar menawar serta tidak adanya produk fisik termasuk aktivitas yang dapat disebut dengan jual beli jasa.Melihat seberapa besar 
pengaruh word of mouth terhadap purchase intention melalui brand image lembaga kursus bahasa inggris pare kediri (Ruhamak \& Rahayu, 2016)

Kotler dan Keller (2016:214) jasa adalah: "any act or that one party can offer another that is essensially intangible and does not result in the ownership of anything. It's production may or not to be tied to a physical product”. "jasa atau layanan adalah semua tindakan atau kinerja yang dapat ditawarkan satu pihak kepada pihak lain yang pada intinya tidak berwujud dan tidak menghasilkan kepemilikan apapun. Produksinya dapat atau tidak terkait dengan produk fisik".

Pada dasarnya pengaruh word of mount untuk mengetahui minat kepada konsumen dan brand image terhadap keputusan konsumen (Ruhamak \& Husniati, 2018).Strategi komunikasi promosi dari mulut ke mulut yang saat ini menjadi salah satu strategi promosi yang menjadi fenomena menarik dan sangat hangat untuk di bicarakan kita sebut dengan Word of Mouth.

WOMMA (Word of Mouth Marketing Association) dalam Sumardy (2011:68) dan (Ruhamak, Vitasmoro, \& Rahmadi, 2018) menjelaskan bahwa "Word of mouth (WOM) merupakan usaha pemasaran yang memicu konsumen untuk membicarakan, mempromosikan, merekomendasikan, dan menjual produk/ merek kita kepada konsumen lainnya".

Sebelum melakukan pembelian maupun penggunaan barang dan jasa, brand image di jadikan prioritas utama dalam proses tersebut. Untuk menciptakan persepsi yang positif terhadap merek suatu barang atau jasa, perusahaan harus dapat menciptakan suatu merek sesuai dengan keinginan dan konsumen serta dapat menarik dan mengambarkan manfaat produk maupun jasa tersebut.

Syahreza (2015) menuturkan bahwa "Brand Image adalah sekumpulan asosiasi merek yang terbentuk dibenak konsumen serta sejumlah keyakinan tentang merek".

Menurut Tjiptono (2014:21) "keputusan pembelian adalah sebuah proses dimana konsumen mengenal masalahnya, mencari informasi mengenai produk atau merek tertentu dan mengevaluasi seberapa baik masing-masing alternatif tersebut dapat memecahkan masalahnya, yang kemudian mengarah kepada keputusan pembelian”.

Membuat keputusan untuk membeli suatu produk atau jasa dengan mengevaluasi nilainya adalah sesuatu yang menarik. Permintaan konsumen menyebabkan para 
pengusaha di berbagai daerah berkompetisi demi menyusun kapasitas barang atau jasa mereka agar sesuai dengan yang di kehendaki konsumen.

\section{Rumusan Masalah}

1. Apakah Word Of Mouth (WOM) berpengaruh secara parsial terhadap Keputusan Penggunaan Jasa Foto pada 4 Warna Photography?

2. Apakah Brand Image berpengaruh parsial terhadap Keputusan Penggunaan Jasa Foto pada 4 Warna Photography?

3. Apakah Word Of Mouth (WOM) dan Brand Image berpengaruh secara simultan terhadap Keputusan Penggunaan Jasa Foto pada 4 Warna Photography?

\section{Tujuan Penelitian}

1. Untuk mengetahui pengaruh antara Word Of Mouth (WOM) terhadap Keputusan Penggunaan Jasa Foto pada 4 Warna Photography.

2. Untuk Mengetahui Pengaruh antara Brand image terhadap Keputusan Penggunaan Jasa Foto pada 4 Warna Photography.

3. Untuk Mengetahui Pengaruh antara Word Of Mouth (WOM) dan Brand image teradap Keputusan Penggunaan Jasa Foto pada 4 Warna Photography.

\section{TINJAUAN PUSTAKA}

\section{Word Of Mouth (WOM)}

Secara sederhana definisi komunikasi dilakukan dari mulut ke mulut adalah suatu tindakan yang dilakukan konsumen untuk menyampaikan informasi yang terkait produk oleh konsumen kepada konsumen lain. Komunikasi dari mulut ke mulut merupakan salah satu ciri khusus dalam pelaku bisnis jasa. Pelanggan sering memperhatikan dengan teliti penyerahan jasa dan kemudian menceritakan pengalaman pada pelanggan potensial lainnya (Ihwani, 2013).

WOM pada dasarnya adalah komunikasi informal tentang produk atau jasa (Rahmadi \& Ruhamak, 2018), berbeda dengan komunikasi formal, karena dalam komunikasi informal pembicara cenderung bertindak sebagai seorang teman lebih persuasif. 


\section{Brand Image}

Citra Merek merupakan salah satu hal yang diingat didalam benak konsumen pada saat membeli suatu produk merek tertentu. Menurut Kotler dan Keller (2016) "Citra merek adalah presepsi dan keyakinan yang dipegang oleh konsumen, seperti yang dicerminkan asosiasi yang tertanam dalam ingatan pelanggan, yang selalu diingat pertama kali saat mendengar slogan dan tertanam dibenak konsumenya".

Brand Image merupakan hasil penelitian konsumen terhadap suatu Brand baik atau buruk. Hal ini berdasarkan pertimbangan juga menyeleksi dengan membandingkan perbedaan pada beberapa Brand, hingga Brand yang ditawarkan sesuai dengan kebutuhan yang terpilih. Image merupakan hal yang positif menjadi salah satu hal yang penting tanpa Image yang kokoh sulit bagi perusahaan untuk menarik pelanggan yang baru untuk mempertahankan yang sudah ada.

\section{Keputusan Pembelian}

Pemasar mendalami berbagai pengaruh mengenai pembelian konsumen dan mengembangkan juga pemahaman mengenai bagaimana cara sebenarnya konsumen membuat keputusan pembelian mereka. Konsumen dalam melakukan keputusan pembelian tidak langsung memutuskan membeli suatu produk, akan tetapi konsumen memiliki pertimbangan yang akhirnya memutuskan untuk membeli . Menurut Kotler dan Keller (2012) Keputusan pembelian adalah suatu tindakan konsumen membentuk referensi merek dalam kelompok pilihan dengan membeli produk yang paling disukai oleh pembeli.

\section{Kerangka Berfikir}

Gambar 2.1 : Kerangka Berfikir

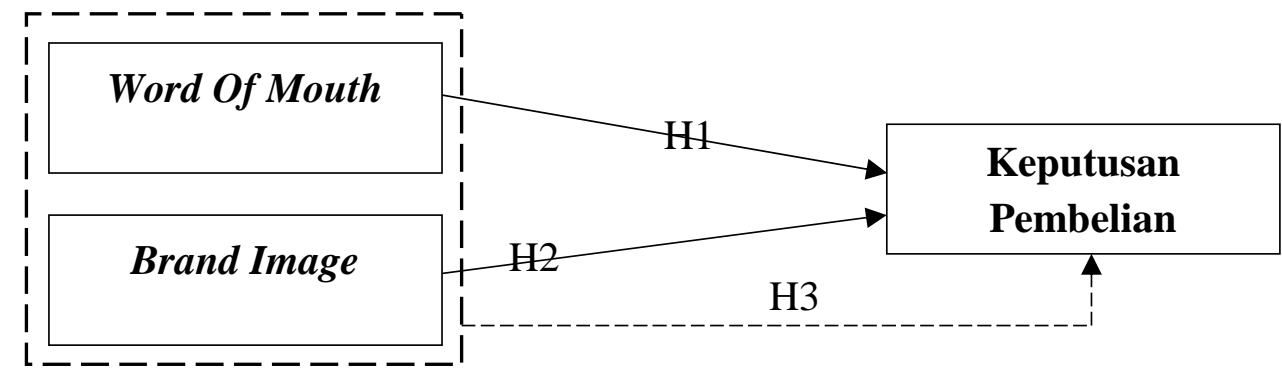

Keterangan: $\longrightarrow$ Berpengaruh Secara Parsial

Berpengaruh Secara Simultan 


\section{Hipotesis}

$\mathrm{H} 1$ = Word Of Mouth (X1) berpengaruh secara signifikan terhadap Keputusan Pembelian (Y)

$\mathrm{H} 2$ = Brand Image $(\mathrm{X} 2)$ berpengaruh secara signifikan terhadap Keputusan Pembelian (Y)

$\mathrm{H} 3$ = Word Of Mouth (X1) dan Brand Image (X2) berpengaruh secara simultan terhadap Keputusan Pembelian (Y)

\section{METODE PENELITIAN}

\section{Populasi Dan Sampel Penelitian}

Menurut Sugiyono (2016 : 117) Populasi adalah wilayah generalisasi terdiri : obyek atau subyek mempunyai kualitas dan karakteristik tertentu ditetapkan peneliti untuk mempelajari kemudian menyimpulkan. Populasi penelitian seluruh pengguna jasa 4 Warna Photography di Kediri.

Menurut Sugiyono (2016 : 118) Sampel adalah jumlah dari karakteristik yang dipunyai populasi . Untuk sampel yang diambil dari populasi harus betul-betul representative (mewakili).

Dalam penelitian ini, jumlah populasinya tidak diketahui sehingga penentuan ukuran sampel dari populasi menggunakan teori dari Roscoe dalam Sugiyono (2016 : 103), anggota sampel minimal 10x dari jumlah variabel (independent + dependent) yang diteliti. Maka jumlah anggota sampel yang diambil 20. Dalam penelitian ini terdapat 3 variabel yang berarti $20 \times 3=60$

\section{Variabel Penelitian}

Menurut Sugiyono (2013:60), variabel penelitian adalah semua yang berbentuk yang ditetapkan oleh peneliti untuk dipelajarinya sehingga diperoleh informasi tersebut kemudian ditarik kesimpulannya.

Variabel-variabel dalam penelitian ini adalah sebagai berikut:

1. Variabel Independen (X)

Variabel bebas merupakan variabel yang dapat dipengaruhi variabel terikat. Dan dapat disimbolkan dengan X (Sugiono, 2016:39). Adapun variabel bebas pada penelitian ini adalah Word Of Mouth (X1), Brand Image (X2). 
2. Variabel Dependen (Y)

Variabel ini biasa disebut sebagai variabel output, kriteria, konsekuensi. Variabel terikat mempengaruhi atau menjadikan akibat, karena adanya variabel bebas (Sugiyono, 2016:39). variabel terikat adalah Keputusan Pembelian (Y).

Tabel. 1 Defini Operasional Variabel

\begin{tabular}{|c|c|c|}
\hline Variabel & Definisi & Indikator \\
\hline $\begin{array}{l}\text { Word Of Mouth } \\
\quad(X 1) \\
\text { ( Rosiana, 2011) }\end{array}$ & $\begin{array}{l}\text { Komunikasi informal produk atau } \\
\text { jasa, berbeda dengan komunikasi } \\
\text { formal, komunikasi informal } \\
\text { pembicara cenderung bertindak } \\
\text { seorang teman yang lebih persuasif. }\end{array}$ & $\begin{array}{ll}\text { - } & \text { Cerita Positif } \\
\text { - } & \text { Rekomendasi } \\
\text { - } & \text { Ajakan }\end{array}$ \\
\hline $\begin{array}{c}\text { Brand Image } \\
(X 2) \\
(\text { Kumala, 2012) }\end{array}$ & $\begin{array}{l}\text { Sekelompok asosiasi merek } \\
\text { terbentuk dipikiran konsumen }\end{array}$ & $\begin{array}{l}\text { - Corporate Image } \\
\text { - Product Image } \\
\text { - User Image } \\
\end{array}$ \\
\hline $\begin{array}{c}\text { Keputusan } \\
\text { Pembelian } \\
(\text { Y) } \\
\text { ( Kotler dan Keller, } \\
\text { 2016) }\end{array}$ & $\begin{array}{l}\text { Suatu tindakan konsumen } \\
\text { membentuk referensi diantara } \\
\text { merek-merek dalam suatu } \\
\text { kelompok pilihan dengan membeli } \\
\text { produk yang paling disukai. }\end{array}$ & $\begin{array}{ll}\text { - } & \text { Pengenalan Masalah } \\
\text { - } & \text { Pencariaan Informasi } \\
\text { - } & \text { Evaluasi Alternatif } \\
\text { - } & \text { Keputusan Penggunaan } \\
\text { - } & \text { Perilaku Pasca } \\
& \text { Pembelian }\end{array}$ \\
\hline
\end{tabular}

\section{Metode Pengumpulan Data}

Adapun teknik pengumpulan data menurut Sugiyono (2016) yang digunakan dalam penelitian ini antara lain sebagai berikut :

1. Kuesioner ( Angket)

Pengumpulan data dilakukan dengan memberi pertanyaan atau pernyataan tertulis kepada responden untuk dijawabnya.

2. Observasi (pengamatan)

Teknik pengumpulan data yang spesifik jika dibandingkan teknik yang lainnya.

3. Wawancara

Pengumpulan data yang dilakukan dengan komunikasi pemilik pelaku usaha yang hingga akhirnya diperoleh suatu data yang diperlukan peneliti.

4. Studi kepustakaan dan penjelajahan internet

Peneliti meneliti studi kepustakaan dengan cara menganalisis berbagai literature yang ada seperti buku, skripsi, dan jurnal, yang berkaitan dengan judul yang telah peneliti sajikan. 


\section{Metode Analisis Data}

\section{Validitas Dan Reliabiitas}

Sujarweni dan Endrayanto (2012) mengatakan bahwa uji validitas digunakan untuk mengetahui kelayakan butir-butir dalam suatu daftar pertanyaan dalam mendefinisikan suatu variabel.

Uji reliabilitas merupakan alat mengukur suatu kuesioner merupakan indikator dari konstruk. kuesioner dikatakan reliable jika jawaban terhadap pertanyaan konsisten. SPSS memberikan fasilitas mengukur reliabilitas Uji Statistik Crobanch Alpha $(\alpha)$. Yang variabel dikatakan reliabel jika nilai $\alpha>0,60$ (Ghozali, 2011:46).Untuk mengukur digunakan patokan :

- Reabilitas uji coba $\geq 0.60$ berarti hasil uji coba memiliki reliabilitas baik.

- Reabilitas uji coba $<0.60$ berarti hasil uji coba memiliki reliabilitas kurang baik Metode Analisis Regresi

Untuk menguji hipotesis tentang kekuatan variabel penentu (independent variable) terhadap keputusan pembelian dalam penelitian ini menggunakan analisis regresi linier berganda dengan persamaan kuadrat terkecil dengan model dasar :

$\mathrm{Y}=\mathrm{a}+\mathrm{b} 1 \mathrm{X} 1+\mathrm{b} 2 \mathrm{X} 2+\mathrm{e}$

\section{Uji Hipotesis}

\section{Uji T Dan Uji F}

Uji $\mathrm{T}$ atau yang sering disebut dengan uji secara parsial bertujuan mengetahui model regresi variabel independent $\mathrm{X} 1$ dan $\mathrm{X} 2$ berpengaruh variabel dependen (Y) dengan asumsi variabel adalah konstan.

Uji $\mathrm{F}$ disebut Uji secara simultan digunakan mengetahui besarnya variabel independent (X1 dan X2) secara bersama-sama berpengaruh variabel dependent (Y). Analisis uji $\mathrm{F}$ dilakukan dengan membandingkan $\mathrm{F}$ hitung dan $\mathrm{F}$ tabel. Sebelum membandingkan nilai $\mathrm{F}$, ditentukan tingkat kepercayaan (1- a) dan derajat kebebasan (degree of freedom $)-n-(k+1)$ agar dapat dituntukan nilai kriterianya.

\section{Koefisien Determinasi}

Koefisien Determinasi (R2) digunakan mengetahui presentase variabel independen secara bersama untuk menjelaskan variabel dependen. Nilai koefisien 
deternimasi nol dan satu jika koefisien determinasi $(\mathrm{R} 2)=1$. Jika koefisien determinasi $(\mathrm{R} 2)=0$.

\section{HASIL DAN PEMBAHASAN}

\section{Deskripsi Penelitian}

4 Warna Photography merupakan sebuah studio foto yang berada di Jl. Penanggungan No. 9B Bandar Lor Kec. Mojoroto Kota Kediri. Secara garis besar kegiatan studio foto terfokus pada proyek buku tahunan sekolah serta foto pernikahan.

Kuesioner yang disebarkan dalam penelitian ini berjumlah 60 kuisioner dengan responden sebagai sampel adalah konsumen studio foto 4 Warna Photography. Kuisioner yang kembali juga berjumlah 60 kuesioner, jadi response rate dalam penelitian ini adalah $100 \%$ yang artinya semua jawaban lengkap dan layak digunakan untuk analisa.

\section{Deskripsi Karakteristik Responden}

\section{Jenis Kelamin}

Adapun karakteristik responden berdasarkan jenis kelamin konsumen 4 Warna Photography dapat dilihat pada tabel :

\section{Tabel 2. Karakteristik Responden Berdasarkan Jenis Kelamin}

\begin{tabular}{|c|c|c|c|}
\hline No. & Jenis Kelamin & Frekuensi & Presentase\% \\
\hline 1 & Laki-Laki & 23 & $38 \%$ \\
\hline 2 & Perempuan & 37 & $62 \%$ \\
\hline & Total & $\mathbf{6 0}$ & $\mathbf{1 0 0 \%}$ \\
\hline
\end{tabular}

Sumber Data : Hasil Pengolahan Data Kuesioner (2019)

Berdasarkan data pada tabel 4.1 menunjukkan bahwa dari 60 yang menjadi responden pada penelitian ini, 23 orang berjenis kelamin laki-laki dengan persentase $38 \%$ dan 37 orang berjenis perempuan dengan persentase $62 \%$ sehingga dapat dinyatakan bahwa jumlah responden berjenis kelamin perempuan lebih banyak dari jumlah responden berjenis kelamin laki-laki.

\section{Usia Responden}

Adapun karakteristik responden berdasarkan jenis kelamin konsumen 4 Warna Photography dapat dilihat pada tabel : 
Tabel 3. Karakteristik Responden Berdasarkan Usia

\begin{tabular}{|c|c|c|c|}
\hline No. & Usia & Frekuensi & Presentase\% \\
\hline 1 & $<17$ Tahun & 29 & $48 \%$ \\
\hline 2 & $17-25$ Tahun & 20 & $33 \%$ \\
\hline 3 & $>25$ Tahun & 11 & $18 \%$ \\
\hline & Total & $\mathbf{6 0}$ & $\mathbf{1 0 0 \%}$ \\
\hline
\end{tabular}

Sumber Data : Hasil Pengolahan Data Kuesioner (2019)

Berdasarkan data pada tabel 4.2 menunjukkan bahwa dari 60 orang yang menjadi responden pada penelitian ini, 29 orang berusia kurang dari 17 tahun dengan persentase 48\%, 20 orang berusia 17-25 tahun dengan presentase 33\% dan 11 orang berusia lebih dari 25 tahun dengan persentase 18\% sehingga dapat dinyatakan bahwa jumlah responden berusia kurang dari 17 tahun lebih banyak dari jumlah responden berusia lebih dari 17 tahun.

\section{Uji Validitas Dan Reliabilitas}

Tabel 4. Hasil Uji Validitas

\begin{tabular}{|l|c|}
\hline Variabel & $\mathbf{r}_{\text {hitung }}$ \\
\hline Word Of Mouth (X1) & $\mathbf{0 , 7 5 1}$ \\
\hline & $\mathbf{0 , 6 6 9}$ \\
\hline & $\mathbf{0 , 7 9 5}$ \\
\hline & $\mathbf{0 , 4 4 5}$ \\
\hline & $\mathbf{0 , 6 4 7}$ \\
\hline & $\mathbf{0 , 7 7 0}$ \\
\hline & $\mathbf{0 , 7 1 2}$ \\
\hline & $\mathbf{0 , 7 2 1}$ \\
\hline & $\mathbf{0 , 5 5 7}$ \\
\hline & $\mathbf{0 , 6 1 9}$ \\
\hline & $\mathbf{0 , 5 0 7}$ \\
\hline Brand Image (X2) & $\mathbf{0 , 7 3 9}$ \\
\hline & $\mathbf{0 , 9 1 7}$ \\
\hline & $\mathbf{0 , 8 6 4}$ \\
\hline & $\mathbf{0 , 8 1 8}$ \\
\hline & $\mathbf{0 , 9 1 7}$ \\
\hline & $\mathbf{0 , 7 3 9}$ \\
\hline & $\mathbf{0 , 7 6 7}$ \\
\hline & $\mathbf{0 , 8 2 3}$ \\
\hline & $\mathbf{0 , 7 4 9}$ \\
\hline & $\mathbf{0 , 7 3 6}$ \\
\hline & \\
\hline
\end{tabular}


Tabel 5. Uji Reliabilitas

\begin{tabular}{|l|c|c|c|}
\hline \multicolumn{1}{|c|}{ Variabel } & $\begin{array}{c}\text { Cronbach's } \\
\text { Alpha }\end{array}$ & $\begin{array}{c}\text { Critical } \\
\text { Velue }\end{array}$ & Keterangan \\
\hline Word Of Mouth $(\mathbf{X 1 )}$ & 0,760 & 0,6 & Reliabel \\
\hline Brand Image $(\mathbf{X 2 )}$ & 0,817 & 0,6 & Reliabel \\
\hline Keputusan Pembelian (Y) & 0,796 & 0,6 & Reliabel \\
\hline
\end{tabular}

\section{Uji Regresi Linier Berganda}

Analisis ini berpengaruh variabel independent (word of mouth dan brand image) terhadap variabel dependent (keputusan pembelian) melalui persamaan variabel yang terbentuk.

Tabel 4.5 : Hasil Uji Regresi Linier Berganda Coefficients $^{\mathrm{a}}$

\begin{tabular}{|c|c|c|c|c|c|c|}
\hline & \multirow[t]{2}{*}{ Model } & \multicolumn{2}{|c|}{$\begin{array}{c}\text { Unstandardized } \\
\text { Coefficients }\end{array}$} & \multirow{2}{*}{$\begin{array}{c}\text { Standardized } \\
\text { Coefficients }\end{array}$} & \multirow[t]{2}{*}{$\mathbf{t}$} & \multirow[t]{2}{*}{ Sig. } \\
\hline & & B & Std. Error & & & \\
\hline \multirow[t]{3}{*}{1} & (Constant) & .819 & 2.159 & & .379 & .706 \\
\hline & $\begin{array}{l}\text { Word of } \\
\text { mouth }\end{array}$ & .288 & .055 & .545 & 5.211 & .000 \\
\hline & Brand image & .310 & .105 & .309 & 2.953 & .005 \\
\hline
\end{tabular}

a. Dependent Variable: Keputusan Pembelian

Sumber: Data Primer di olah dengan SPSS (2019)

Berdasarkan table 4.5 Nilai konstanta sebesar 0,819 menunjukkan bahwa apabila variabel word of mouth $\left(\mathrm{X}_{1}\right)$ dan variabel brand image $\left(\mathrm{X}_{2}\right)$ diabaikan dalam analisis, maka keputusan pembelian (Y) bernilai konstan 0,819 . Koefisien regresi variabel word of mouth $\left(\mathrm{X}_{1}\right)$ diketahui sebesar 0,288 artinya apabila word of mouth meningkat 1 satuan dengan asumsi variabel yang lain konstan, maka keputusan pembelian mengalami peningkatan $28,8 \%$. Koefisien regresi variabel brand image $\left(\mathrm{X}_{2}\right)$ diketahui sebesar 0,310 artinya apabila keputusan pembelian meningkat 1 satuan dengan asumsi variabel yang lain konstan, maka loyalitas konsumen akan mengalami peningkatan sebesar $31 \%$. 


\section{Uji T dan Uji F}

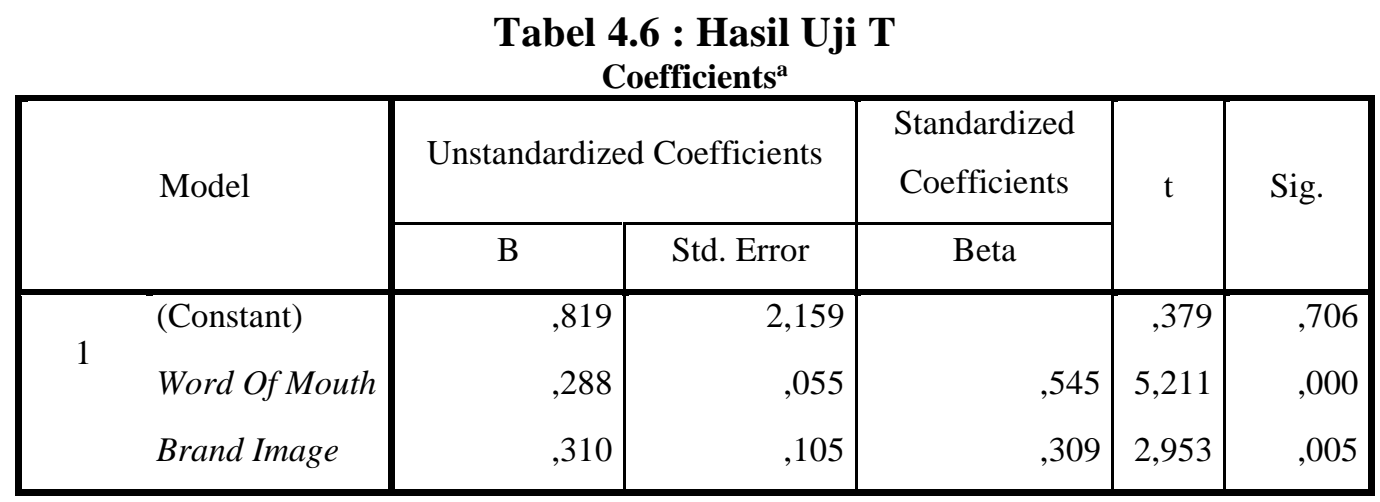

a. Dependent Variable: Keputusan Pembelian

Sumber: Data Primer Di Olah Dengan SPSS (2019)

Berdasarkan tabel 4.6 dapat diketahui bahwa hasil uji regresi parsial sebagai berikut :

Hasil statistik uji t untuk variabel kepuasan konsumen diketahui bahwa nilai thitung sebesar 5,211 dengan nilai signifikansi 0,000 lebih kecil $0,05 \quad(0,000<0,5)$, dan koefisien regresi mempunyai nilai positif sebesar 0,288. Maka secara parsial ada pengaruh signifikan variabel word of mouth terhadap variabel keputusan pembelian. Hasil statistik uji t untuk variabel brand image diketahu bahwa nilai thitung sebesar 2,953 dengan nilai signifikansi sebesar 0,005 dimana kurang dari $0,05(0,005<, 05)$ dan koefisien regresi mempunyai nilai positif sebesar 0,310. Maka secara parsial ada pengaruh yang signifikan antara variabel brand image terhadap variabel keputusan pembelian.

Tabel 4.7 : Hasil Uji F

Anova $^{a}$

\begin{tabular}{|c|r|r|r|r|r|}
\hline Model & Sum of Squares & Df & Mean Square & F & Sig. \\
\hline Regression & 205,188 & 2 & 102,594 & 40,896 &, $000^{\text {b }}$ \\
Residual & 142,995 & 57 & 2,509 & & \\
Total & 348,183 & 59 & & & \\
\hline
\end{tabular}

a. Dependent Variable: Keputusan Pembelian

b. Predictors: (Constant), Brand Image, Word Of Mouth

Sumber: Data Primer di olah dengan SPSS (2019)

Berdasarkan hasil perhitungan pada tabel 4.7 nilai signifikan 0,000. Hal ini menunjukkan nilai signifikan uji $\mathrm{F}$ variabel word of mouth dan brand image 0,000< 0,05 berarti Hasil pengujian secara bersama - sama bahwa word of mouth (X1) dan brand image (X2) berpengaruh signifikan terhadap keputusan pembelian (Y). 


\section{Koefisien Determinasi}

Koefisiensi determinasi digunakan mengetahui berapa besar pengaruh variabel bebas memiliki pengaruh terhadap variabel terikatnya. Nilai koefisiensi determinasi ditentukan dengan nilai adjusted $R$ square .

Tabel 4.8 : Koefisien Determinasi

Model Summary

\begin{tabular}{|l|r|r|r|r|}
\hline Model & R & R Square & \multicolumn{1}{|c|}{$\begin{array}{c}\text { Adjusted R } \\
\text { Square }\end{array}$} & $\begin{array}{l}\text { Std. Error of } \\
\text { the Estimate }\end{array}$ \\
\hline 1 & $.768^{\mathrm{a}}$ & .589 & .575 & 1.584 \\
\hline
\end{tabular}

a. Predictors: (Constant), Brand Image, Word Of Mouth

Sumber: Data Primer di olah dengan SPSS (2019)

Berdasarkan output tabel 4.8 diketahui nilai $\mathrm{R}$ Square 0,589 , hal ini mengandung arti bahawa pengaruh variabel word of mouth dan brand image secara simultan terhadap variabel Y sebesar 58,9\%. Sementara sisanya sebesar $41,1 \%$ di pengauruhi oleh variabel lain yang tidak di teliti dalam penelitian ini.

\section{KESIMPULAN DAN SARAN}

\section{Kesimpulan}

Dari hasil penilitian yang dilakukan berkaitan dengan pengaruh word of mouth dan brand image terhadap keputusan pembelian, maka dapat disimpulkan :

1. Hasil pengujian secara parsial menunjukkan pengaruh signifikan antara variabel word of mouth terhadap variabel keputusan pembelian yang dibuktikan dengan nilai signifikansi 0,000 dimana lebih kecil dari $0,05(0,000<0,05)$.

2. Hasil pengujian secara parsial menunjukkan bahwa berpengaruh secara signifikan antara variabel brand image terhadap variabel keputusan pembelian dengan nilai signifikansi 0,005 lebih kecil dari 0,05 $(0,005<0,05)$.

3. Hasil perhitungan nilai signifikan 0,000 . bahwa nilai signifikan uji $\mathrm{F}$ variabel word of mouth dan brand image $<0,05$ berarti hasil pengujian simultan adalah word of mouth dan brand image berpengaruh keputusan pembelian.

\section{Saran}

Bagi Perusahaan

Manajemen selalu meningkatkan pemasarannya dengan memberikan informasi cepat dan detail tentang brand image 4 Warna Photograhy. Menanggapi keluhan konsumen serta mampu mengatasi masalah yang dihadapi konsumen. Hal ini dilakukan agar konsumen merasa dihargai dan mendapakan pelayanan yang baik agar keputusan pembelian tetap ada. 
Bagi Peneliti Selanjutnya

Saran bagi peneliti selanjutnya adalah sebagai berikut :

1. Peneliti selanjutnya diharapkan mengambil sampel yang lebih banyak sehingga hasil penelitian lebih valid.

2. Peneliti selanjutnya diharapkan dapat menganalisis variabel lain yang memberikan kontribusi terhadap keputusan pembelian.

3. Peneliti selanjutnya diharapkan dapat mengkaji lebih dalam tentang word of mouth dan brand image yang berpengaruh terhadap keputusan pembelian agar hasil yang didapat bisa lebih lengkap dan lebih baik lagi.

\section{DAFTAR PUSTAKA}

Fandy, Tjiptono. 2014. Pemasaran Jasa - Prinsip, Penerapan, dan Penelitian. Yogyakarta: Andi Offset.

Ghozali, Imam. 2011. Aplikasi Analisis Multivariate dengan Program SPSS. Semarang: Badan penerbit Universitas Diponegoro.

Ihwani, Azmi Ulil Mufti. 2013. Pengaruh Word of Mouth Communication Terhadap Keputusan Santri Memilih Pondok Pesantren. Yogyakarta: Universitas Islam Negeri Sunan Kalijaga. Skripsi

Kotler, Philip and Kevin Lane Keller. 2012. Marketing Management, 13th. New Jersey: Pearson Prentice Hall, Inc.

Kotler, Philip and Kevin Lane Keller. 2016. Marketing Management, 15th Edition. New Jersey: Pearson Pretice Hall, Inc.

Kumala, Octaviantika Benazir. 2012. Pengaruh Word Of Mouth Terhadap Minat Beli Konsumen Pada Tune Hotels Kuta-Bali. Jakarta: Universitas Indonesia. SkripsiRosiana, D. 2011. Pengaruh E-Servequal Terhadap Nilai Pelanggan, Kepuasan Dan Word Of Mouth Communication Anggota Situs Jejaring Social Facebook. Denpasar: Universitas Udayana. Skripsi

Rahmadi, A. N., \& Ruhamak, M. D. (2018). Pengaruh Customer Relationship Management (CRM) dan Word of Mouth (WOM) Terhadap Kinerja Usaha Pada Usaha Kecil Menengah di Kota Kediri. EkoNiKa Jurnal Ekonomi Universitas Kadiri, 3(2), 208-216.

Ruhamak, M Dian, \& Rahayu, B. (2016). Pengaruh Word Of Mouth Terhadap Purchase Intention Melalui Brand Image Pada Lembaga Kursus Bahasa Inggris Dynamic English Course Pare. Ekonika: Jurnal Ekonomi Universitas Kadiri, 1(2).

Ruhamak, Muhammad Dian, \& Husniati, E. (2018). Pengaruh Word Of Mouth , Minat Konsumen Dan Brand Image Terhadap Keputusan Konsumen ( Studi Pada Pelajar Lembaga Kursus Di Area Kampung Inggris Pare Kediri ). EKONIKA: Jurnal Ekonomi Universitas Kadiri, 3(2), 118-135.

Ruhamak, Muhammad Dian, Vitasmoro, P., \& Rahmadi, A. N. (2018). The Influence of Testimonial, Social Media-based Promotions and Electronic Word of Mouth toward Purchase Intention, (1), 78-81.

Sugiyono. 2016. Metode Penelitian Kuantitatif, Kualitatif dan R\&D. Bandung: Alfabeta. 
Sujarweni, V. W., \& Endrayanto, P. 2012. Statistika Untuk Penelitian. Yogyakarta: Graha Ilmu.

Syahreza, A. Muh. 2015. Pengaruh Brand Image Terhadap Keputusan Penggunaan Jasa Penerbangan Pada PT. Garuda Indonesia Cabang Makassar. Makassar: Universitas Hasanuddin. Skripsi 